\title{
Possible Micrometeorological Anomalies Induced by Volcanic Activity Recorded at Stromboli Island (Aeolian Archipelago, Italy)
}

\author{
Paolo Madonia, Marianna Cangemi, and Salvatore Inguaggiato \\ Istituto Nazionale di Geofisica e Vulcanologia, Sezione di Palermo, Via Ugo La Malfa 153, 90146 Palermo, Italy \\ Correspondence should be addressed to Paolo Madonia; paolo.madonia@ingv.it
}

Received 3 May 2015; Revised 22 July 2015; Accepted 13 August 2015

Academic Editor: Anthony R. Lupo

Copyright (C) 2015 Paolo Madonia et al. This is an open access article distributed under the Creative Commons Attribution License, which permits unrestricted use, distribution, and reproduction in any medium, provided the original work is properly cited.

Hourly values of atmospheric pressure and air temperature have been acquired at the top of two volcanic islands, Stromboli and Salina in the Aeolian Archipelago (Italy), very similar in height and morphology but completely different with regard to their volcanic activity state: the former is permanently active, whereas the latter is extinguished. During the last four years Stromboli experienced normal activity, volcanic unrests, and an effusive eruption (August-November 2014). The comparative analysis of the recorded data, both in the time and frequency domains, evidenced a peculiar micrometeorological regime at Stromboli, more turbulent during unrests with respect to the quieter periods, but showing an apparent paradox during eruptions, characterized by a lower atmospheric turbulence. These observations suggest that the studied volcanic-micrometeorological system is chaotic, due to contemporary opposite transients generated in the atmosphere by volcanic activity changes, and that micrometeorological conditions in volcanic areas are controlled both by exogenous processes and volcanic activity.

\section{Introduction}

The mutual causal relationships between volcanic activity and climate, as in the present as in the whole geological record, have been widely investigated during the last decades. Volcanoes have affected Earth's climate through the injection in the atmosphere of gases and solid particles, whose primary effect is the reduction of incoming solar energy at Earth's surface, due to the scattering of solar radiation by secondary aerosols formed from volcanic sulphur [1]. Conversely, climatic changes could act as an external forcing for volcanic activity [2]. Volcanic aerosol injected in the atmosphere has been claimed as a catalyst for possible atmospheric pressure disturbances induced by solar magnetic storms (the socalled Wilcox effect) [3]. Although large-scale phenomena have attracted the interest of many researchers, processes at meteorological and micrometeorological scale are not as well known as the former. Abrupt atmospheric pressure transients, strong winds, and heavy rains influence soil degassing in volcanic areas $[4,5]$ and, under particular conditions, can act as a trigger for energetic volcanic events [6].
If we look at the other side of the coin, that is, the possible effect of volcanic activity on the local meteorological regime, less information is available. Stromboli Island, an active volcano part of the Aeolian volcanic arch (Italy, Figure 1), due to its mild explosive and effusive activity permanent during the last centuries [7], represents an ideal location for such research hypotheses. During its 2002-2003 eruption Brusca et al. [4] identified wind and air temperature anomalies on the top of the volcano, driven by volcanic activity. A more recent study by Madonia et al. [8] extended to atmospheric pressure the range of these anomalies, at the net of a possible external forcing due to a Wilcox-like effect.

With the aim of giving new clues on the role played by volcanic activity in controlling local meteorological conditions, here we report about the comparison between atmospheric pressure and air temperature data acquired hourly at Stromboli and Salina islands, both located in the Aeolian Archipelago (Figure 1). During the study period, April 2011April 2015, Stromboli experienced very different activity states, ranging from the background degassing to an effusive eruption through energetic unrests $[9,10]$. This variability 


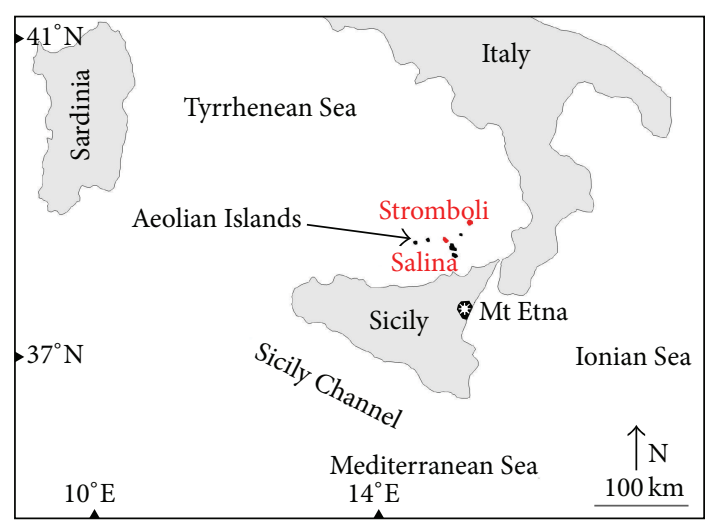

(a)

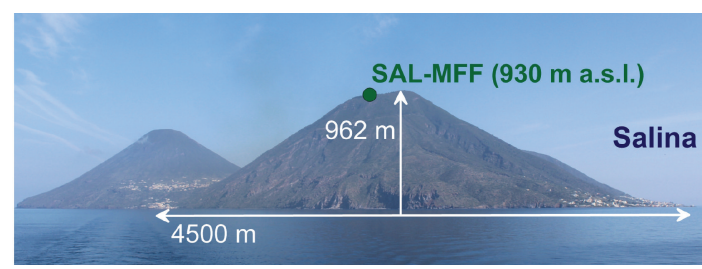

(b)

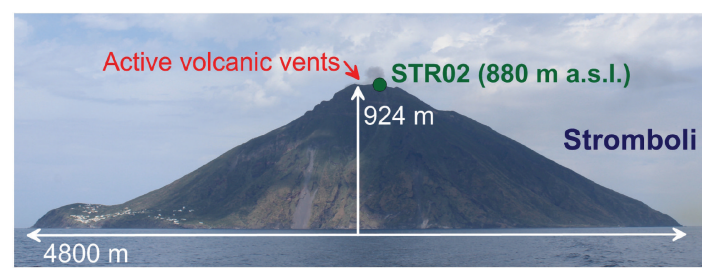

(c)

FIgURE 1: From the top to the bottom, location map of the studied area (a) and pictures taken from the south side to Salina (b) and Stromboli (c) islands, indicating width and height of the volcanic edifices and location of the monitoring stations (elevation between brackets) used for the acquisition of micrometeorological data.

gave us the opportunity of looking for possible micrometeorological anomalies driven by volcanic activity, hereafter debated.

\section{Materials and Methods}

2.1. Materials. Meteorological data, as atmospheric pressure, air temperature and relative humidity, and wind speed and direction, have been acquired since the early 2000's with an hourly period as side parameters in a volcano monitoring station (STR02, Figure 1(c)), located close to the top of Stromboli Island at $880 \mathrm{~m}$ a.s.l., few hundreds of meters apart from the active volcanic vents. The station is based on a West System datalogger, equipped with a barometric sensor Vaisala Barocap PTB 110 and an air temperature sensor Lastem DNA 520 , ensuring a resolution of $\pm 0.03 \mathrm{hPa}$ and an accuracy of $\pm 1.5 \mathrm{hPa}$ and of $\pm 0.2^{\circ} \mathrm{C}$ and $\pm 0.04^{\circ} \mathrm{C}$, respectively. Both pressure and temperature data series are discontinuous, due to system failures caused by the extremely adverse operative conditions, typical of active volcanic areas (mainly due to acidic gas corrosion and mechanical damages consequent to the impact with volcanic ejecta).

A comparative station (SAL-MFF, Figure 1(b)) was installed in April 2011 at an altitude of $930 \mathrm{~m}$ a.s.l. on the top of Mount Fossa delle Felci, the easternmost of the twin volcanic edifices constituting Salina Island, located about $40 \mathrm{~km}$ south-westward of Stromboli (Figure 1(a)). As shown in the pictures taken of the islands from the South (Salina and Stromboli, Figures 1(b) and 1(c), resp.), these are characterized by very similar conical shapes, with base diameters of c.a. $4.5 \mathrm{~km}$ and heights of c.a. $900 \mathrm{~m}$ a.s.l., ensuring a comparable orographic control on the local micrometeorological regimes. The Salina station is based on a four-channel, 12-bit Onset Microstation datalogger, equipped with barometric and temperature Smart Sensors, with a resolution of $\pm 0.1 \mathrm{hPa}$ and an accuracy of $\pm 3 \mathrm{hPa}$ and of $\pm 0.2^{\circ} \mathrm{C}$ and $\pm 0.03^{\circ} \mathrm{C}$, respectively. Data cover continuously the study period, with a single stop in the acquisition between February and April 2013 due to a malfunction of the datalogger batteries.

2.2. Methods. The main aim of our work was highlighting possible micrometeorological anomalies at Stromboli, driven by volcanic activity, through the comparison with atmospheric pressure and air temperature data acquired at the same instant at Salina, where a "normal" atmospheric circulation is expected. In doing this, we first normalized the hourly data acquired at Stromboli with respect to Salina by the formulae

$$
\begin{aligned}
& P_{\text {nor }}^{\mathrm{STR}}=\frac{P_{i}^{\mathrm{STR}}}{P_{i}^{\mathrm{SAL}},} \\
& T_{\text {nor }}^{\mathrm{STR}}=\frac{T_{i}^{\mathrm{STR}}}{T_{i}^{\mathrm{SAL}}},
\end{aligned}
$$

where the apices "STR" and "SAL" refer to Stromboli and Salina, respectively, and the pedicle " $i$ " refers to the $i$-esim hour. Since we analysed pressure ratios, we did not correct data for the bias due to the small difference in elevation between the stations $(50 \mathrm{~m})$.

Normalized data were analysed both in the time and frequency domains. In the time domain, we first built the cumulative probability plot for both parameters, in order to highlight possible different statistical families related to different physical processes. After this, we plotted the data on chronograms, reporting the main volcanic phases experienced by Stromboli and the separation limits between "normal" and "anomalous" values (as resulting from the probability plots), looking for any possible volcanic-dependent micrometeorological anomaly.

In the frequency domain, we applied the fast Fourier transform (FFT) analysis to atmospheric pressure data for evaluating possible frequency content variations potentially induced by volcanic activity. We selected two different subperiods with continuous data, covering the same seasonal interval in order to remove any astronomic effect, but embracing two different volcanic activity states. In particular, we considered the subperiod August 2011-February 2012, 
encompassing a volcanic unrest, and the equivalent time window comprised between August 2012 and February 2013, characterized by a quieter volcanic activity. Pressure data covering the 2014 eruption, as well as the whole record of temperature, were affected by frequently missing data and for this reason were not analysed by FFT (requiring continuous time series).

Probability plots and FFT analysis were performed using the freeware KY plot.

2.3. Volcanic Activity at Stromboli. Stromboli volcano is characterized by an open-conduct degassing system with a continuous, peculiar explosive activity, referred to as "Strombolian activity." It takes place from the upper vents, located at about $750 \mathrm{~m}$ a.s.l., and consists of passive degassing alternated to short (up to few tens of s) 100 to $200 \mathrm{~m}$ high jets, produced by explosions of variable energy every 10-20 min [11-13].

The normal Strombolian activity is occasionally disrupted by unrest periods, characterized by more frequent and energetic explosions and lava overspills from the summit vents.

In recent times 4 effusive eruptions occurred at Stromboli (1985, 2002-2003, 2007, and 2014). These took place from eruptive fissures opened at altitudes comprised between 400 and $650 \mathrm{~m}$ a.s.l. $[10,14]$ on the Sciara del Fuoco, a scar cut into the NW flank of the volcano along which the emitted lava flows down to the sea. During effusive eruptions, the upper portion of the conduit (comprised between the vents and the effusive fractures) is emptied and activity from the vents ceases at all, renewing after the end of the eruptions through a transitional irregular phase.

\section{Results and Discussion}

3.1. Results. The cumulative probability plots for atmospheric pressure and air temperature ratios between Stromboli and Salina, hereafter referred to as $\operatorname{Pr}$ and $\mathrm{Tr}$, are illustrated in Figures 2 and 3. As shown in the figures, the distribution of both $\operatorname{Pr}$ and $\operatorname{Tr}$ values is assignable to a single family with a quasi-Gaussian distribution, without abrupt slope changes in the curve indicating different data groups. Consequently, we set the discriminant between normal and anomalous values using percentiles as criterion: data within the 5th and the 95th percentile were considered as normal, whereas anomalies were referred to measures falling outside this interval. Normal Pr values are comprised within a band about one order of magnitude narrower (0.004, Figure 2) than Tr data (0.034, Figure 3); a similar behaviour is found for anomalous data, whose ranges (excluding outliers) are 0.03 and 0.08 for Pr and Tr, respectively.

Chronograms illustrating $\operatorname{Pr}$ and $\mathrm{Tr}$ variations, the 5th and 95th percentile thresholds and the main volcanic events are illustrated in Figures 4 and 5. The classification of $\mathrm{Pr}$ data (Figure 4), based on the anomaly thresholds, allows the identification of three different periods. The first one (a), spanning from the beginning of the observations (April 2011) to the first half of May 2012, includes the 2011 unrest [9] and is characterized by a high scattering of data, with both positive and negative anomalies. It is followed by a quieter

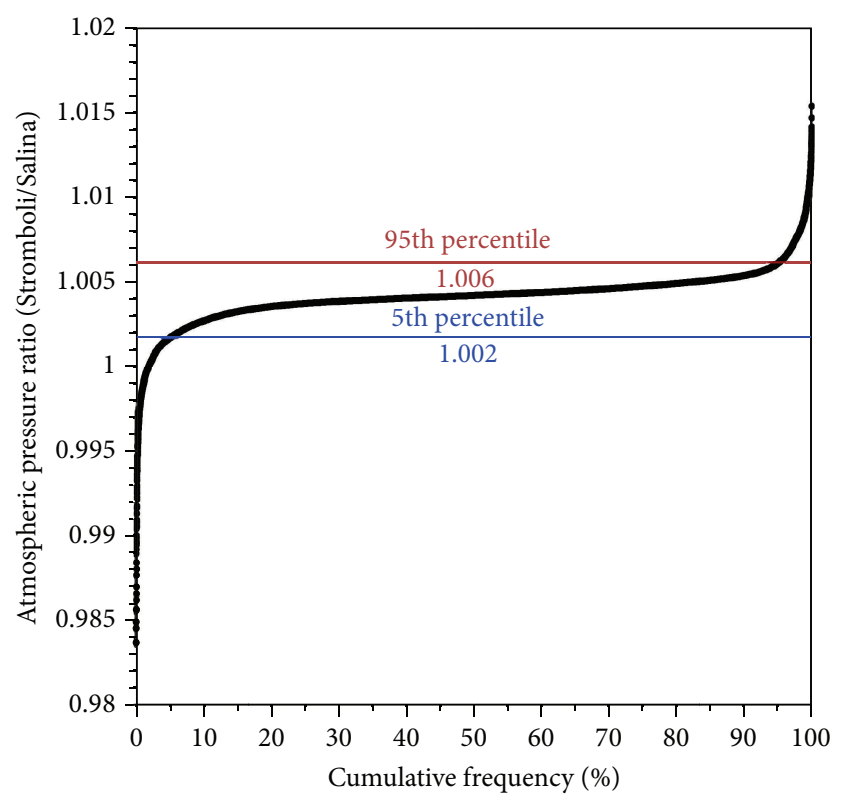

FIGURE 2: Cumulated probability plot of the hourly atmospheric pressure ratios between Stromboli and Salina islands (Pr), with indication of the 5 th and 95 th percentiles.

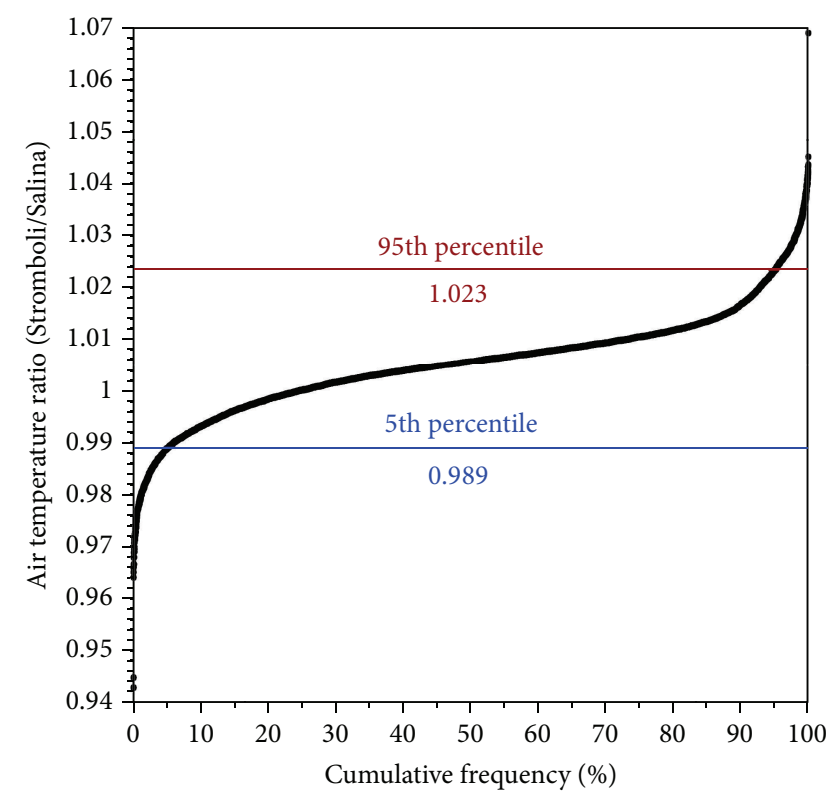

FIGURE 3: Cumulated probability plot of the hourly air temperature ratios between Stromboli and Salina islands ( $\mathrm{Tr}$ ), with indication of the 5 th and 95 th percentiles.

period (b), lasting until the first days of January 2014 at least (missing data between January and June 2014), with the most of data included within the normality band. Pressure data were available on June 2014 again (onset of period (c)), characterized by intense negative $\mathrm{Pr}$ anomalies that occurred during a second unrest, followed by an effusive eruption [10], after which new intense negative Pr anomalies were recorded. It is noteworthy that during both the 2011 lava overspills and 


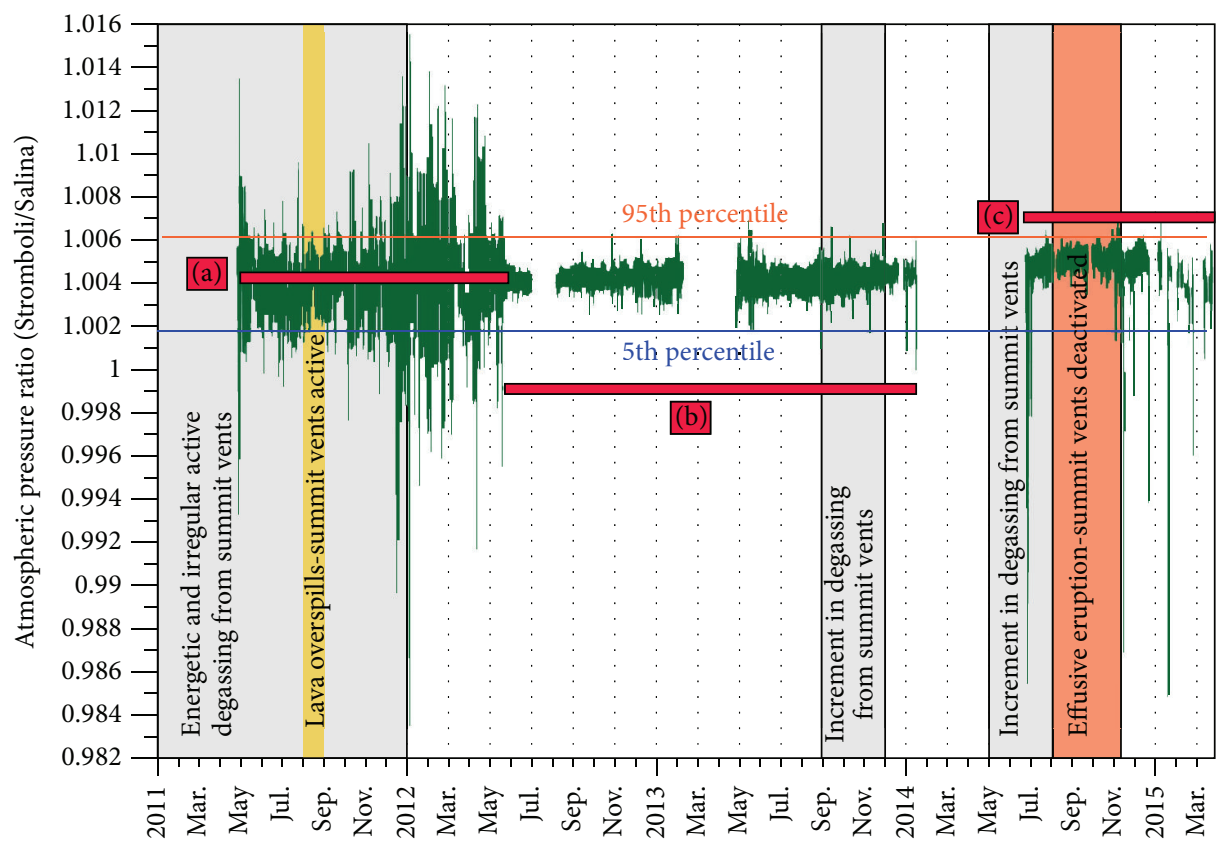

FIGURE 4: Chronogram of the hourly atmospheric pressure ratios between Stromboli and Salina islands (Pr) measured during the study period (April 2011-April 2015), with indication of the 5th and 95th percentiles. Vertical bands describing the volcanic activity state are drawn from literature data $[9,10]$ and the periodic bulletins emitted by INGV (http://www.ingv.it/it/). The lettered ((a)-(c)) horizontal red bands indicate intervals characterized by different variation styles in Pr signal (see main text for further details).

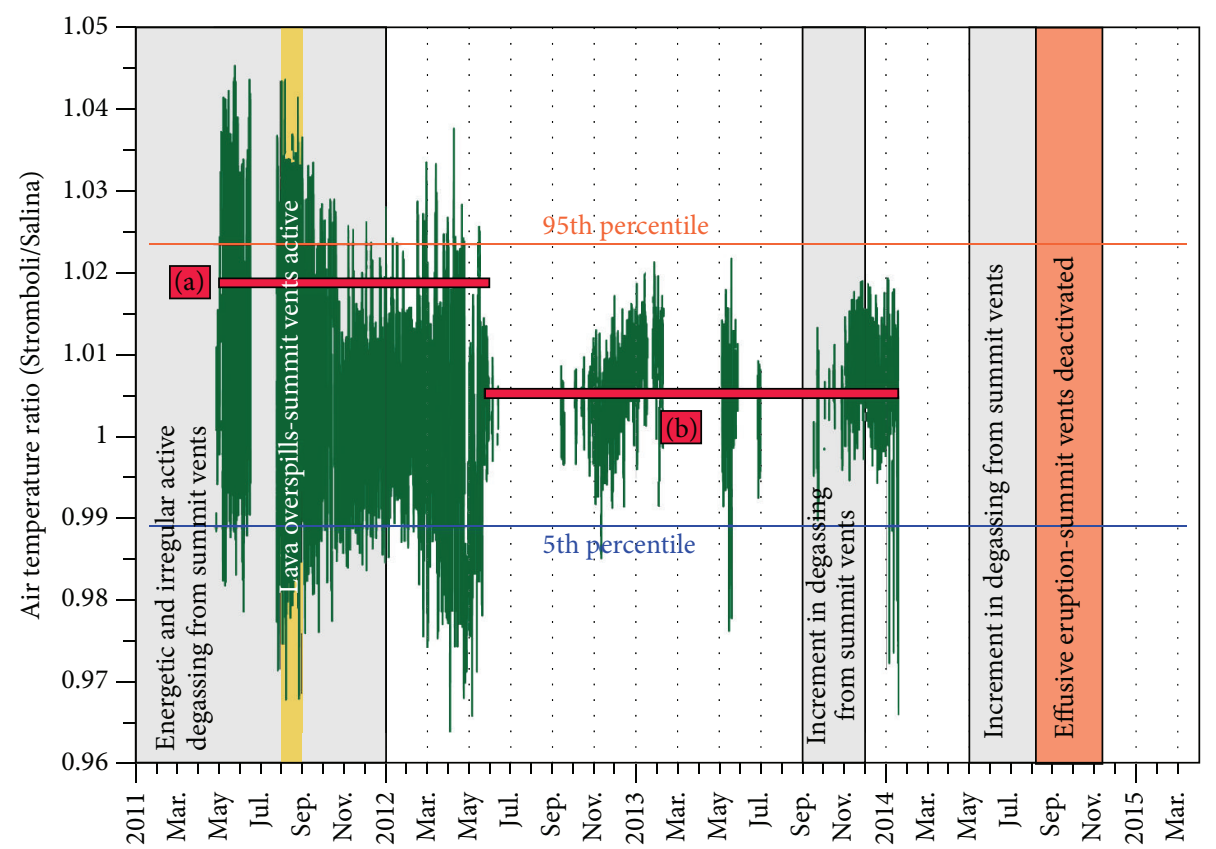

FIGURE 5: Chronogram of the hourly air temperature ratios between Stromboli and Salina (Tr) measured during the study period (April 2011-April 2015), with indication of the 5th and 95th percentiles. Air temperature data from Stromboli have been no more available since February 2014. Vertical bands describing the volcanic activity state are drawn from literature data $[9,10]$ and the periodic bulletins emitted by INGV (http://www.ingv.it/it/). The lettered ((a)-(b)) horizontal red bands indicate intervals characterized by different variation styles in Pr signal (see main text for further details). 


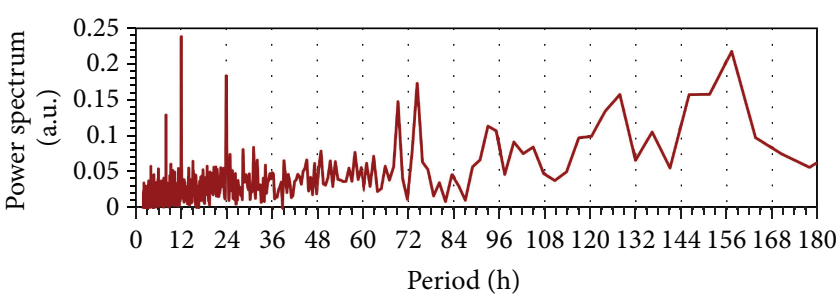

— August 2011-February 2012

(a)

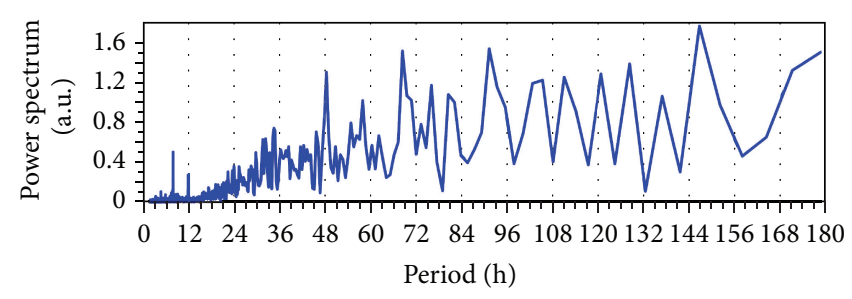

_ August 2012-February 2013

(b)

FIGURE 6: Power spectra obtained by FFT applied to the hourly atmospheric pressure ratios between Stromboli and Salina islands. (a) (brick red line, August 2011-February 2012) refers to the turbulent period embracing the 2011 volcanic unrest, compared to the equivalent quieter period of the next year (August 2012-February 2013, blue line in (b)). Data related to the eruptive period (August 2014-February 2015) are discontinuous, not allowing FFT analysis. Both curves start at 2 hours for removing aliased data determined by sampling period (1 hour).

the 2014 effusive period the Pr signal showed less scattering than during the adjacent time windows.

As expected from the related probability plot (Figure 3) the $\mathrm{Tr}$ signal (Figure 5) showed a general larger variability. Although the identification of different variation styles is not simple, due to frequent and long-lasting missing data periods, two periods ((a), (b)) with the same characteristics of those identified for Pr data are visible. Unfortunately, the behaviour of Tr signal during the 2014 eruption was not evaluable, since the temperature sensor got out of order.

Similar information, but in the frequency domain, were given by the spectrograms obtained by FFT and reported in Figure 6. The frequency contents, characterizing the subperiods previously discussed, show several dissimilarities. The first period, comprised within the interval (a) described in Figures 4 and 5, exhibits evident components at 12, 24, and 8 hours (listed for decreasing amplitudes). Conversely, the component at 24 hours disappears in the second period (interval (b) in Figures 4 and 5), replaced by an evident peak at 48 hours. Secondary features of the spectra are two peaks at 70 and 75 hours for the interval August 2011-February 2012 (Figure 6(a)), replaced by a positive drift of the baseline starting at 14 hours and a single peak at 70 hours for the interval August 2012-February 2013 (Figure 6(b)).

3.2. Discussion. The comparison of atmospheric pressure and air temperature data acquired at Stromboli with those measured at Salina indicates that volcanic activity could generate micrometeorological anomalies. As shown in Figures 4 and 5, both $\operatorname{Pr}$ and $\operatorname{Tr}$ signals exhibited a wider scattering when volcanic activity was more energetic (periods (a), (c)), with a pronounced coda covering the transition to normal strombolian activity. These signals oscillated within a narrower band (period (b)) when Stromboli rested at a regular background level of degassing from the vents.

Prior to assign to volcanic activity changes the origin of these anomalies, measuring errors, or natural causes able to influence micrometeorological signals should be excluded. Among the possible disturbances, the following could play a major role in affecting our data: calibration drifts in sensors or crossing of meteorological frontiers causing pressure differential between Stromboli and Salina. Calibration drifts should result in a progressive bias between our signals, but we did not observe any signal drift in the chronograms. Moreover, the observed anomalies were short lasting transients, poorly disturbed by a possible bias of their baselines. Disturbances due to atmospheric frontiers crossing the area seem also to be unlike, because (a) the main atmospheric perturbations come in the Mediterranean from NW (North Atlantic circulation), and since Stromboli and Salina lie along a direction orthogonal to this one, their distance projected along the main frontier direction is very small; (b) during the anomalous period identified as "(a)" in Figures 4 and 5 pressure anomalies lasted up to a month, showing a duration not compatible with much shorter phenomena as frontier crossings; (c) crossings of atmospheric frontiers occur every year, but we observed frequent pressure anomalies between the second half of 2011 and the first half of 2012, nothing in the same period of the following year and again a different signal two years later; if frontier crossings were able to influence pressure signals, we should observe this phenomenon every year. Due to the abovementioned reasons, disturbances induced by measuring errors or larger scale meteorological phenomena should be excluded, suggesting that changes in volcanic activity state could drive micrometeorological anomalies.

The first and simplest approach in relating $\operatorname{Pr}$ and $\operatorname{Tr}$ anomalies to volcanic activity is the black box model: since both signals, in the time domain, showed a wider scattering during phases of increased volcanic activity and the following period of transitions to normal conditions (Figures 4 and 5), a causal relationship between endogenous and atmospheric phenomena is suggested. The frequency domain analysis (FFT, Figure 6) points to the same conclusions: spectrograms of the Pr signal acquired in different time windows, characterized by different volcanic activity states, show different frequency contents, suggesting that different processes drove atmospheric pressure variations during each period. A serious issue in the development of the following analytical step, for example, the implementation of quantitative models able to link Pr and Tr signals to some physical tracer of volcanic activity, consists in the chaotic structure of these processes, presumably dominated by transients generated under selforganized criticality (SOC) conditions. The reason why these 
processes are chaotic dwells in the contemporary opposite effects generated by volcanic activity on Pr and Tr signals.

A paradigmatic example is given by contemporary air heating and cooling due to volcanic activity. Air heating over volcanoes is driven by two main processes, often coacting: radiative heating of atmospheric air and injection of hot volcanic gases, which mainly constituted of $\mathrm{H}_{2} \mathrm{O}$ [15], in the atmosphere.

The radiative heat transfer from soil to the near ground atmosphere is a normal phenomenon driving air temperature. The difference between a "normal" and a volcanic area is that in the former the Sun is the main source of thermal energy, and in the latter soil could receive additional energy by advection of volcanogenic vapour which, other than be discharged in the atmosphere as a plume from the vents, is released through the soil (fumarolic activity) [4]. Since the volcanogenic vapour flux is variable in time, according to the activity state of the volcano, higher air temperatures are expected during phases of high volcanic activity and vice versa. An additional contribution is given when lava fields are active. Lava is emitted at a temperature of about $1000^{\circ} \mathrm{C}$ [16], with average flow rates up to the order of several $\mathrm{m}^{3} \mathrm{~s}^{-1}$ in case of effusive eruptions due to the opening of eruptive fractures at the base of the summit vents [17], heating air, and generating a strong turbulence over Stromboli $[4,8]$.

The injection of hot, pressurized gases in the atmosphere, during the frequent explosions (average period 20 minutes) characterizing the peculiar volcanic activity of Stromboli (the so-called "Strombolian" activity) [7], generate volume and pressure fronts detected by the station as temperature and pressure transients. As well as soil radiative heating, amplitude and frequency of explosions are not constant in time, but these can significantly change according to the activity state of the volcano [9], driving the variable turbulence of $\mathrm{Pr}$ and Tr signals previously described.

On the contrary, during period of high volcanic activity the greater water vapour flow emitted in the atmosphere is responsible for an inverse-phase effect on air temperatures. Volcanogenic vapour emitted by the summit vents quickly condensates in liquid phase, generating hydrometeors and incrementing cloudiness over Stromboli, hence in turn causing air cooling due to the shield effect with respect to solar heating. Another negative feedback on air temperature, occurring during effusive eruptions, is given by the deactivation of the summit vents and the downslope, northwestward migration of both lava emission and degassing activity, due to the opening of eruptive fractures at the base of the crater terrace $[4,10]$. Under typical effusive conditions, thermal activity is generated in an area farther from the monitoring station with respect to its location during the normal strombolian activity: the final effect is an apparently paradoxical diminution of air turbulence over the summit area of Stromboli during lava effusions, as recorded by the lower scattering shown by the Pr signal during the 2011 lava overspills and the 2014 eruption (Figure 4).

Another clue of the extreme complexity of the volcanicmicrometeorological system is given by the different behaviour of the Pr signal during the 2011-2012 and 2014 unrests (Figure 4). During the former, degassing was very intense and explosions were energetic [9], generating positive atmospheric pressure transients. During the latter, magma was very high in the conduits feeding the summit vents, but with a minor amount of gas involved [10], boosting explosions less energetic than during normal strombolian conditions (authors' direct observation in July '14), revealed by the absence of positive transients in the Pr signal during that period (Figure 4).

\section{Conclusions}

The general lesson learnt by the comparative analysis of atmospheric pressure and air temperature data, collected on summit stations located at Stromboli and Salina islands, is that the functional relationships between volcanoes and atmosphere are more complicated than they could appear. The common way to look at the micrometeorological regime of sites instrumented for volcano monitoring is that atmospheric parameters represent an exogenous noise affecting the volcanic signal. On the other hand, our data demonstrate that micrometeorological conditions are on their own influenced by volcanic activity, creating a chaotic, causal loop in the mass and energy exchanges between volcanoes and the atmosphere. This consideration suggests that natural systems need to be considered from a holistic perspective for correctly discriminating between real signals and unwanted noises.

\section{Conflict of Interests}

The authors declare that there is no conflict of interests regarding the publication of this paper.

\section{Acknowledgments}

This research was carried out on behalf of the monitoring program of Italian active volcanoes, financially supported by the Italian National Department of Civil Protection (DPCN). The authors wish to thank all the personnel of INGV, Sezione di Palermo, involved in the maintenance of the Stromboli station STR02, without whose hard work this study could not have been realized. The authors also wish to thank two anonymous reviewers: thanks to their suggestions and constructive criticisms they improved the overall quality of this paper.

\section{References}

[1] J. Cole-Dai, "Volcanoes and climate," Wiley Interdisciplinary Reviews: Climate Change, vol. 1, no. 6, pp. 824-839, 2010.

[2] W.-J. McGuire, R.-J. Howarth, C.-R. Firth et al., "Correlation between rate of sea-level change and frequency of explosive volcanism in the Mediterranean," Nature, vol. 389, no. 6650, pp. 473-476, 1997.

[3] B.-A. Tinsley, J.-T. Hoeksema, and B.-N. Baker, "Stratospheric volcanic aerosols and changes in air-earth current density at solar wind magnetic sector boundaries as conditions for the Wilcox tropospheric vorticity effect," Journal of Geophysical Research, vol. 99, no. 8, pp. 16805-16813, 1994. 
[4] L. Brusca, S. Inguaggiato, M. Longo, P. Madonia, and R. Maugeri, “The 2002-2003 eruption of Stromboli (Italy): evaluation of the volcanic activity by means of continuous monitoring of soil temperature, $\mathrm{CO}_{2}$ flux, and meteorological parameters," Geochemistry, Geophysics, Geosystems, vol. 5, no. 12, Article ID Q12001, 2004.

[5] P. Madonia, P. Cusano, I. S. Diliberto, and M. Cangemi, "Thermal anomalies in fumaroles at Vulcano island (Italy) and their relationship with seismic activity," Physics and Chemistry of the Earth, vol. 63, pp. 160-169, 2013.

[6] D. Patanè, M. Mattia, G. Di Grazia et al., "Insights into the dynamic processes of the 2007 Stromboli eruption and possible meteorological influences on the magmatic system," Geophysical Research Letters, vol. 34, no. 22, 2007.

[7] F. Barberi, M. Rosi, and A. Sodi, "Volcanic hazard assessment at Stromboli based on review of historical data," Acta Vulcanologica, vol. 3, pp. 173-187, 1993.

[8] P. Madonia, P. Romano, and S. Inguaggiato, "Decoupling of ground level pressures observed in Italian volcanoes: are they driven by space weather geo-effectiveness?" Annals of Geophysics, vol. 57, no. 3, 2014.

[9] S. Calvari, A. Bonaccorso, P. Madonia et al., "Major eruptive style changes induced by structural modifications of a shallow conduit system: the 2007-2012 Stromboli case," Bulletin of Volcanology, vol. 76, no. 7, pp. 1-15, 2014.

[10] A.-L. Rizzo, C. Federico, S. Inguaggiato et al., "The 2014 effusive eruption at Stromboli volcano (Italy): inferences from soil $\mathrm{CO}_{2}$ flux and ${ }^{3} \mathrm{He} /{ }^{4} \mathrm{He}$ ratio in thermal waters," Geophysical Research Letters, vol. 42, no. 7, pp. 2235-2243, 2015.

[11] M. R. Patrick, A. J. L. Harris, M. Ripepe, J. Dehn, D. A. Rothery, and S. Calvari, "Strombolian explosive styles and source conditions: insights from thermal (FLIR) video," Bulletin of Volcanology, vol. 69, no. 7, pp. 769-784, 2007.

[12] D. Andronico, R. A. Corsaro, A. Cristaldi, and M. Polacci, "Characterizing high energy explosive eruptions at Stromboli volcano using multidisciplinary data: an example from the 9 January 2005 explosion," Journal of Volcanology and Geothermal Research, vol. 176, no. 4, pp. 541-550, 2008.

[13] J. Taddeucci, P. Scarlato, A. Capponi et al., "High-speed imaging of Strombolian explosions: the ejection velocity of pyroclasts," Geophysical Research Letters, vol. 39, no. 2, Article ID L02301, 2012.

[14] S. Calvari, R. Büttner, A. Cristaldi et al., "The 7 September 2008 Vulcanian explosion at Stromboli volcano: multiparametric characterization of the event and quantification of the ejecta," Journal of Geophysical Research, vol. 117, no. 5, Article ID B05201, 2012.

[15] P. Allard, J. Carbonnelle, N. Métrich, H. Loyer, and P. Zettwoog, "Sulphur output and magma degassing budget of Stromboli volcano," Nature, vol. 368, no. 6469, pp. 326-330, 1994.

[16] A. Harris, J. Dehn, M. Patrick, S. Calvari, M. Ripepe, and L. Lodato, "Lava effusion rates from hand-held thermal infrared imagery: an example from the June 2003 effusive activity at Stromboli," Bulletin of Volcanology, vol. 68, no. 2, pp. 107-117, 2005.

[17] M. Neri and G. Lanzafame, "Structural features of the 2007 Stromboli eruption," Journal of Volcanology and Geothermal Research, vol. 182, no. 3-4, pp. 137-144, 2009. 

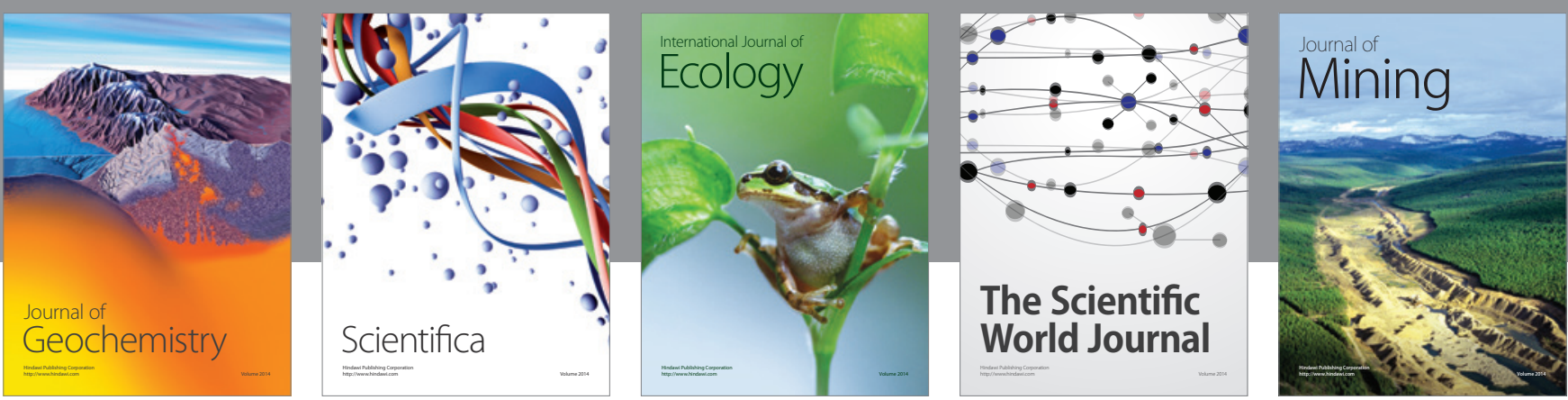

The Scientific World Journal
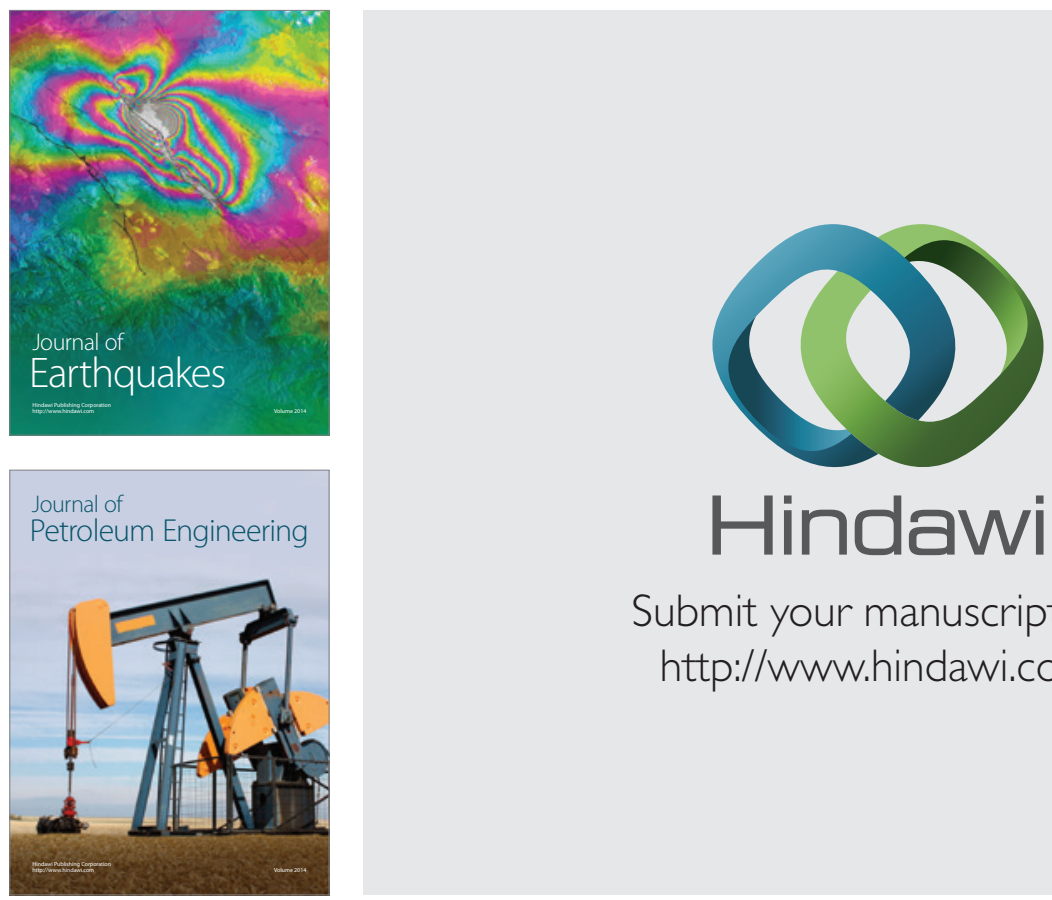

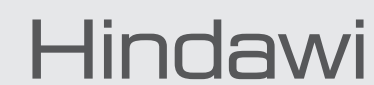

Submit your manuscripts at

http://www.hindawi.com
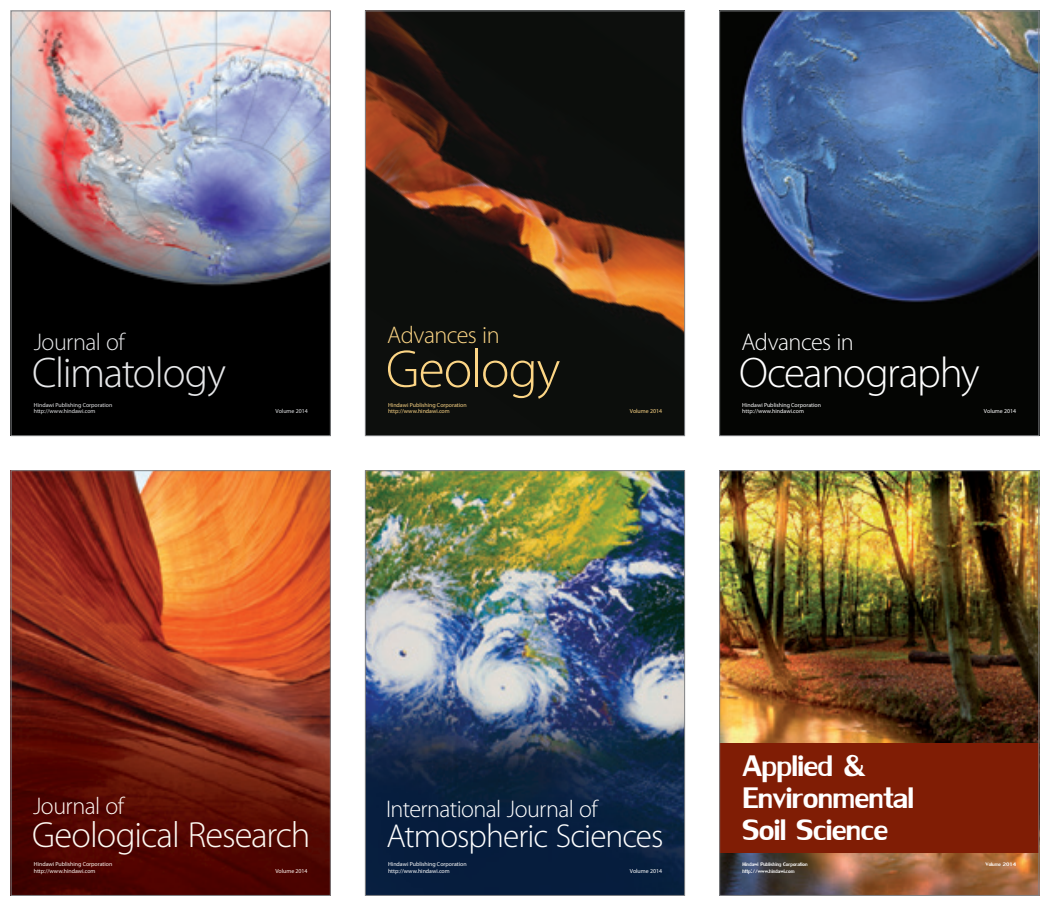
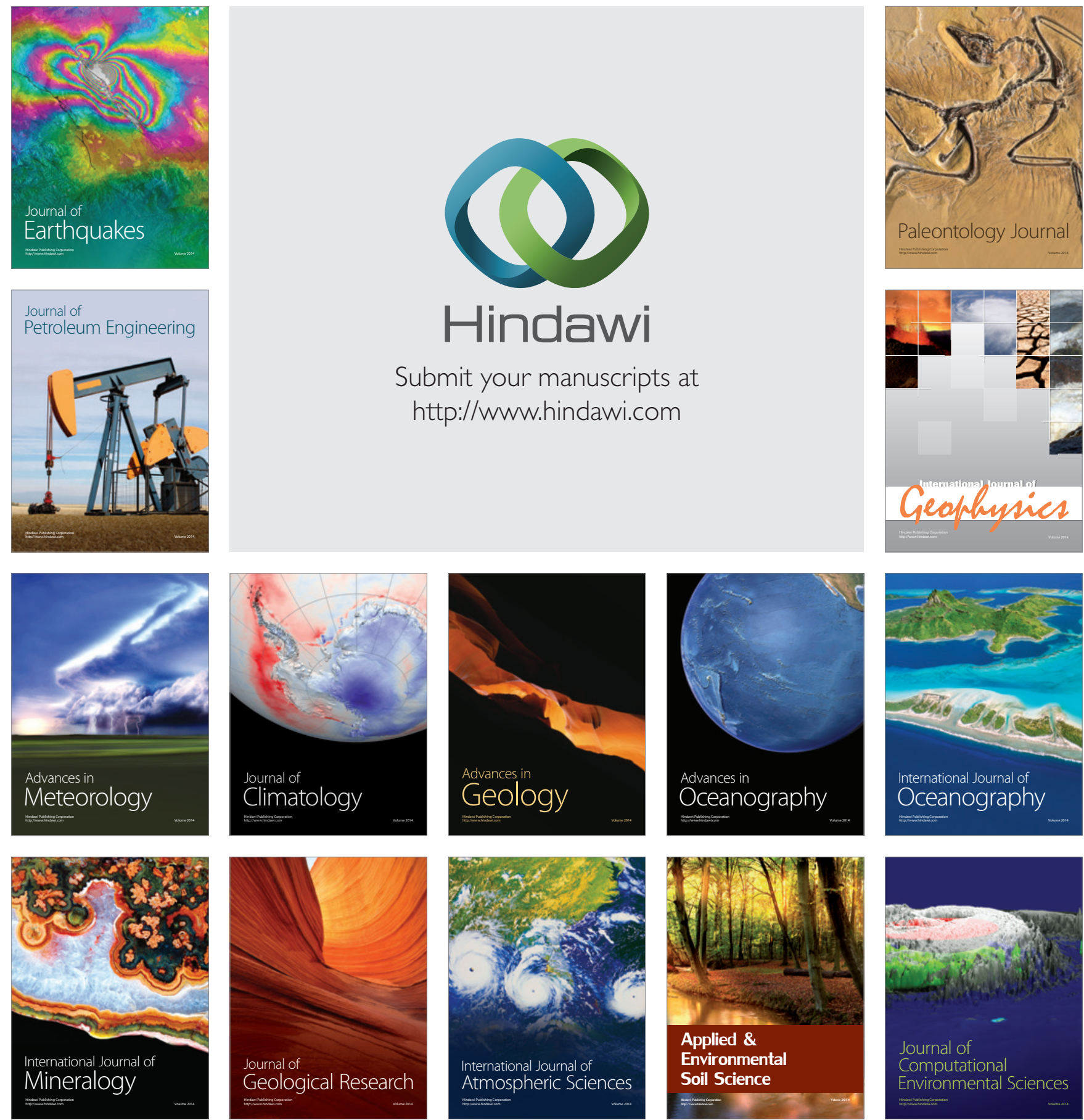